\title{
Expression and regulation of connexin43 in rat Leydig cells
}

\author{
S You, $\mathbf{W}$ Li and $\mathbf{T} \operatorname{Lin}^{\mathbf{1}}$ \\ Medical and Research Services, W J B Dorn Veterans Medical Center, Columbia, South Carolina 29201, USA \\ ${ }^{1}$ Department of Medicine, University of South Carolina School of Medicine, Columbia, South Carolina 29208, USA \\ (Requests for offprints should be addressed to T Lin, Department of Medicine, University of South Carolina School of Medicine, \\ Medical Library Building Suite 316, Columbia, South Carolina 29208, USA; Email: lin@dcsmserver.med.sc.edu)
}

\begin{abstract}
Gap junctions are intercellular protein channels which provide a pathway for the exchange of ions and small molecules. This exchange of materials allows metabolic coupling of cells. Gap junction channels are made up of connexins, integral membrane proteins encoded by a multigene family. Rat testes contain mRNAs for at least five different connexins: Cx26, Cx32, Cx33, Cx37 and $\mathrm{Cx} 43$. Immunocytochemical studies have shown that Cx43 assembles gap junctions between Leydig cells. The present study investigated the expression and regulation of the $\mathrm{Cx} 43$ gene in rat Leydig cells. Purified Leydig cells were obtained from 40- to 80-day-old Sprague-Dawley rats using a combination of arterial perfusion, collagenase digestion, centrifugal elutriation and Percoll gradient centrifugation. Leydig cells from 20- and 30-day-old rats were isolated without arterial perfusion or centrifugal elutriation. Cx43 mRNA was present in 20-day-old rat Leydig cells, reached a plateau at day 40 , and remained at high levels in 65- and 80-day-old rat Leydig cells. To evaluate the regulation of $\mathrm{Cx} 43$ gene expression, Leydig cells were cultured overnight and then treated with human chorionic gonadotropin (hCG) for variable periods of time. Addition of hCG $(10 \mathrm{ng} / \mathrm{ml})$ increased cytochrome P450 side-chain cleavage and steroidogenic acute regulatory protein mRNA levels and testosterone for-
\end{abstract}

mation. However, Cx43 mRNA levels were inhibited by hCG in a time- and dose-dependent manner. Cx43 mRNA levels decreased $27 \%$ as early as $2 \mathrm{~h}$ after the addition of hCG and decreased $60 \%$ by $24 \mathrm{~h}$. Treatment of Leydig cells with 8-bromo-cAMP $(0 \cdot 1 \mathrm{mM})$ for 6 and $24 \mathrm{~h}$ also reduced Cx43 mRNA levels by 36 and 56\% respectively. Primary cultured Leydig cells stained strongly positive with anti-Cx43 monoclonal antibody. Treatment with hCG for $24 \mathrm{~h}$ reduced $\mathrm{Cx} 43$ signals and caused $\mathrm{Cx} 43$ to redistribute to the periphery of the cells. To evaluate the regulation of $\mathrm{Cx} 43$ in vivo, rats were treated with hCG (300 ng i.p.) and testes were removed $24 \mathrm{~h}$ later. Frozen section of testes revealed that these interstitial cells stained positive for $3 \beta$-hydroxysteroid dehydrogenase ( $3 \beta-\mathrm{HSD}$ ) by histochemical staining and were positive for $\mathrm{Cx} 43$ by immunofluorescence staining. The adjacent seminiferous tubules stained only weakly positive for Cx43. Twentyfour hours after hCG treatment, 3 $\beta-\mathrm{HSD}$ activity increased while $\mathrm{Cx} 43$ immunostaining of Leydig cells was reduced. In conclusion, gap junction channels of Leydig cells are regulated by hCG both in vivo and in vitro. hCG increased Leydig cell steroidogenesis and steroidogenic enzyme mRNA levels but caused a redistribution of Cx43.

Journal of Endocrinology (2000) 166, 447-453

\section{Introduction}

Gap junctions are intercellular protein channels that provide a pathway for the exchange of ions and small molecules. This exchange of materials allows electrical and metabolic coupling of cells. Metabolic coupling via gap junctions involving the exchange of metabolites and second messengers has been implicated in embryonic development and control of cell growth (Loewenstein 1979, 1981, Caveney 1985, Goodenough et al. 1996, Kumar \& Gilula 1996).

Connexins are the principal protein components of gap junctions. The connexin is organized into a basic unit of structure, the connexon, which is a hexameric structure with a toroid appearance. The family of connexin proteins includes at least 13 members in rodents and 5 of them (Cx26, Cx32, Cx33, Cx37 and Cx43) have been identified in various types of testicular cells using specific antibodies and/or cDNAs. An individual connexon from one cell docks or associates with a corresponding connexon on a neighboring cell to form a gap junction channel, and multiple channels, in turn, cluster or aggregate in the plane of the membrane to form gap junction plaques (Goodenough et al. 1996, Kumar \& Gilula 1996).

The extensive intercellular coupling between Leydig cells has been demonstrated both in vitro and in situ (Kawa 1987, Risley et al. 1992, Varanda \& Campos de Carvalho 1994). Immunocytochemical studies have shown that Cx43 assembles gap junctions between Leydig cells (Risley et al. 1992, Pellitier 1995, Tan et al. 1996). 
Junctional properties of Leydig cells mechanically dissociated from mouse testes have also been characterized by dye injection and electrophysiological measurements. These cells were found to be extensively coupled (Varanda \& Campos de Carvalho 1994). Western blot analysis using purified Leydig cells confirmed the presence of $\mathrm{Cx} 43$ (Varanda \& Campos de Carvalho 1994). The present study investigated the expression and regulation of the Cx43 gene in rat Leydig cells.

\section{Materials and Methods}

\section{Isolation and purification of rat Leydig cells}

Male Sprague-Dawley rats were obtained from Charles Rivers (Raleigh, NC, USA). The animals were freely fed rat chow and maintained on a $12 \mathrm{~h}$ light: $12 \mathrm{~h}$ darkness cycle. Animals were killed by $\mathrm{CO}_{2}$ asphyxiation prior to dissection. Highly purified Leydig cells were isolated from 40-, 55-, 65- and 80-day-old rat testes using a combination of arterial perfusion, collagenase digestion, centrifugal elutriation and Percoll gradient centrifugation as described by Klinefelter et al. (1987) with minor modification (Lin et al. 1992). The protocol was approved by the local Animal Study Committee. Leydig cells from 20- and 30-day-old rats were isolated without arterial perfusion and centrifugal elutriation. Freshly isolated Leydig cells were plated in $100 \mathrm{~mm}$ culture dishes and incubated at $37^{\circ} \mathrm{C}$ in a humidified atmosphere of $95 \%$ air $/ 5 \% \mathrm{CO}_{2}$ overnight. The medium was removed and replaced with fresh medium containing human chorionic gonadotropin (hCG) $(10 \mathrm{ng} / \mathrm{ml})$ or 8-bromo-cAMP (Sigma, Chemical Co., St Louis, MO, USA) $(0 \cdot 1 \mathrm{mM})$. Cultures were continued for an additional $2-24 \mathrm{~h}$ and total RNA was extracted. Supernatants were centrifuged and stored at $-20{ }^{\circ} \mathrm{C}$ for testosterone RIA as described previously (Lin 1985). The highly specific anti-testosterone antibody cross-reacted only $7 \%$ with $5 \alpha$-dihydrotestosterone and less than $1 \%$ with other steroids (progesterone, $17 \alpha$-hydroxyprogesterone, pregnenolone, androstenedione, estrone and estradiol). All samples from a single study were analyzed in a single assay.

\section{Northern blot hybridization}

Total RNA of Leydig cells was isolated with TRIzol Reagent (Life Technologies, Inc., Gaithersburg, MD, USA). Twenty micrograms RNA per well were loaded in a $2 \%$ agarose denatured gel. After $5 \mathrm{~h}$ electrophoresis at $55 \mathrm{~V}$, the RNA was transferred to a positively charged nylon membrane (Ambion, Austin, TX, USA). The hybridization was carried out at $65{ }^{\circ} \mathrm{C}$ overnight. The antisense RNA probes for $\mathrm{Cx} 43$ gene (the template plasmid cDNA from Dr David Kiang, University of Minnesota, Minneapolis, MN, USA) and $\beta$-actin gene
(pTRI-beta-actin mouse control template cDNA, from MAXIscript kit, Ambion), were generated with a MAXIscript in vitro transcription kit (Ambion) and labeled with a BrightStar Psoralen-Biotin Nonisotopic labeling kit (Ambion) and detected with the BrightStar BioDetect Nonisotopic detection kit (Ambion). The cytochrome P450 side-chain cleavage (P450 scc) cDNA (from Dr JoAnne Richards, Houston, TX, USA) or steroidogenic acute regulatory protein (StAR) cDNA (from Dr Douglas M Stocco, Lubbock, TX, USA) probes were labeled with $\left[\alpha-{ }^{32} \mathrm{P}\right] \mathrm{dCTP}$ with a Random Primers DNA Labeling system (Gibco-BRL, Grand Island, NY, USA) and hybridization was performed at $42{ }^{\circ} \mathrm{C}$ overnight (Lin et al. 1998). The membranes were exposed to Kodak XAR 5 film with an intensifier screen at $-80{ }^{\circ} \mathrm{C}$ for 2 days.

The photographs were scanned with the Scanmaker III scanner (Microtek, Redondo, CA, USA) and quantified with the Sigmascan Pro 4 program (Sigma). Our previous study has shown that both P450 scc and StAR mRNA levels were up-regulated by hCG in a time- and dosedependent manner (Lin et al. 1998). P450 scc or StAR mRNA levels were used in the present study to monitor the response of Leydig cells to hCG treatment. Transcription of the $\beta$-actin gene, which was not affected by any of these treatments, was used as the internal control for each specimen.

\section{Immunofluorescence staining}

Leydig cells were isolated and cultured in two-well chamber slides (Lab-Tek Chamber Slide; Nalge Nunc International, Naperville, IL, USA) overnight. The cells were treated with hCG $(10 \mathrm{ng} / \mathrm{ml})$ for $24 \mathrm{~h}$.

To evaluate in vivo effects of hCG on $\mathrm{Cx} 43$ gene expression, 65-day-old rats were treated with hCG (300 ng i.p.) and testes removed $24 \mathrm{~h}$ later. Freshly isolated rat testes were immediately frozen in liquid nitrogen and kept at $-80{ }^{\circ} \mathrm{C}$ for storage. Five-micron sections were cut and mounted on 3-aminopropyltriethoxy-silane (Sigma)coated slides. The tissue and cell slides were both fixed in $10 \%$ buffered formalin for $15 \mathrm{~min}$ and washed with PBS, then incubated in avidin, biotin blocking solution (Avidin/Biotin Blocking kit; Vector, Burlingame, CA, USA) and 5\% BSA /PBS buffer (containing 0.02\% Triton $\mathrm{X}-100$ ) for $15 \mathrm{~min}$ at room temperature respectively. The monoclonal anti-Cx43 antibody (Chemicon MAB 3068, Temecula, CA, USA), diluted 1:50 in the above BSA/ PBS buffer, was applied to the sections and they were incubated at $4{ }^{\circ} \mathrm{C}$ overnight. The biotinylated second antibody from the Vectastain ABC kit (Universal kit, Vector) was used as conjugator. After washing with PBS, the sections were labeled with streptavidin fluorescein for $75 \mathrm{~min}$ (at $3.6 \mu \mathrm{g} / \mathrm{ml}$ ). The sections were covered with cover-slides with Vectashield mounting medium (Vector), examined microscopically and photographed 
A

\section{$2030 \quad 4055 \quad 65$ 80-day-old}
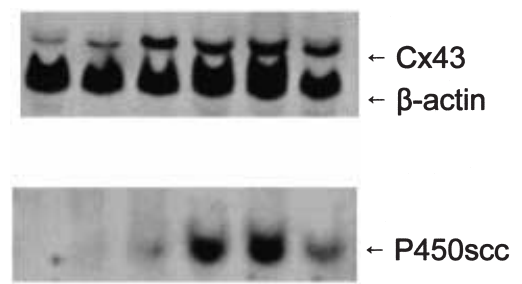

B

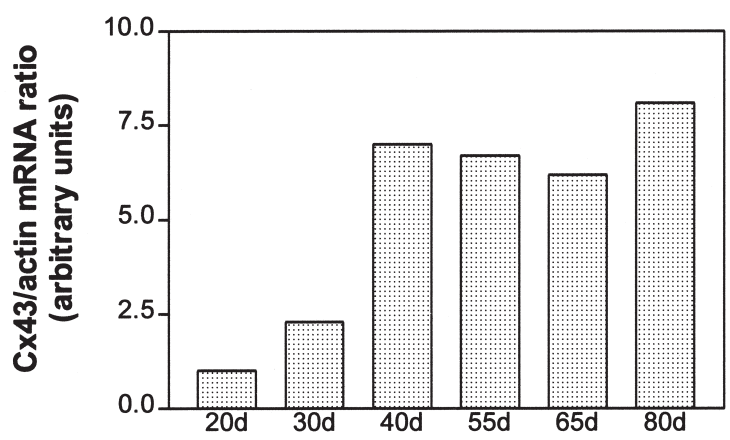

Figure 1 Effects of age on Cx43 gene expression. Leydig cells were isolated from 20-, 30-, 40-, 55-, 65- and 80-day-old rats as described in Materials and Methods. Total RNAs were extracted for Northern blot analyses. Each lane contained $20 \mu \mathrm{g}$ total RNA. The blot was first hybridized with antisense Cx43 and $\beta$-actin RNA probes generated with a MAXIscript in vitro transcription kit and labeled with a BrightStar Psoralen-Biotin Nonisotope labeling kit. P450 scc cDNA probe was labeled with $\left[\alpha{ }^{32} \mathrm{P}\right] \mathrm{dCTP}$. (A) A representative Northern blot; similar results were observed in two other separate experiments. (B) Cx43/actin mRNA ratios.

with a confocal microscope (BioRad MRC 1000; Bio-Rad, Richmond, CA, USA). Quantification of Cx43 immunofluorescence content was performed with the Sigmascan Pro 4 program (Sigma).

\section{Histochemical staining}

Histochemical staining for $3 \beta$-hydroxysteroid dehydrogenase (3ß-HSD) enzyme activity was carried out as reported by Klinefelter et al. (1987). Frozen section testis slides or air-dried purified Leydig cells were covered with staining solution prepared by mixing solution A (1 $\mathrm{mg}$ nitroblue tetrazolium dissolved in $0.6 \mathrm{ml} 1 \mathrm{mg} / \mathrm{ml}$ etiocholanolone in dimethylsulfoxide) with solution $\mathrm{B}$ (10 mg $\beta-N A D+$ in $9 \cdot 5 \mathrm{ml}$ warm PBS). Tissue slides or cells were allowed to stain for $90 \mathrm{~min}$, rinsed in distilled water, and fixed in 10\% formalin in PBS with $5 \%$ sucrose, pH 7·4 (Klinefelter et al. 1987). As assessed by 3ß-HSD staining, more than $95 \%$ of the cells were stained positive for Leydig cells.

\section{A $\quad$ C $24 \quad 4 \quad 6 \quad 24 \mathrm{~h}$}
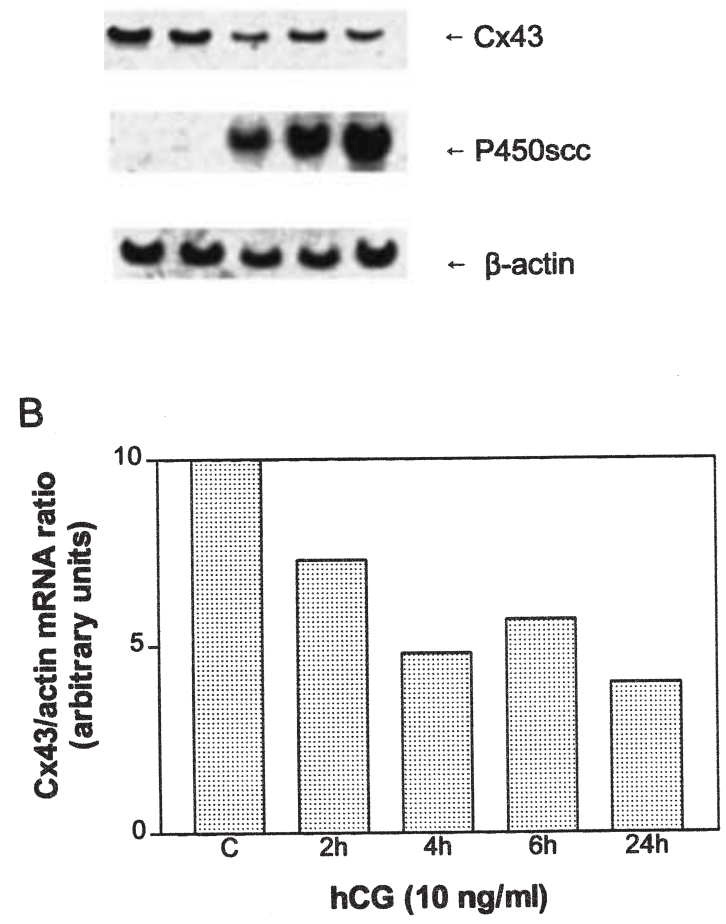

Figure 2 Effects of hCG on Cx43 gene expression. Purified Leydig cells were obtained from 55- to 65-day-old rats. Cells were cultured overnight and then treated with hCG $(10 \mathrm{ng} / \mathrm{ml})$ for 2, 4, 6 or $24 \mathrm{~h}$. Total RNAs were extracted for Northern blot analyses. (A) A representative Northern blot; similar results were obtained with two separate experiments. (B) Cx43/actin mRNA ratios.

\section{Statistical analyses}

All experiments were repeated at least three times. Oneway ANOVA followed by Newman-Keuls multiple comparison tests were used for statistical analyses (GraphPad Prism, Version 2.01, GraphPad Software Inc., San Diego, CA, USA). $P \leq 0.05$ was considered significant.

\section{Results}

Ontogeny of Cx43 gene expression in developing rat Leydig cells

We first evaluated the transcription of the $\mathrm{Cx} 43$ gene in freshly isolated Leydig cells from different age rats, 20-80 days old. As shown in Fig. 1, P450 scc mRNA levels progressively increased as Leydig cells matured. Only a very faint band was observed with $\mathrm{Cx} 43$ antisense probe hybridization in the RNA from day 20 rat Leydig cells. By day 30, Cx43 mRNA levels increased about 2 -fold. The 
A $\quad 0 \quad 10 \quad 1 \quad 0.1 \mathrm{ng} / \mathrm{ml} \mathrm{hCG}$
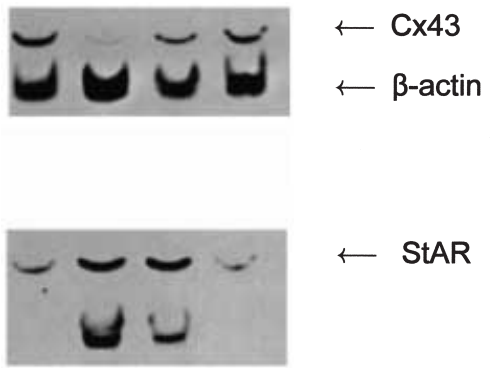

$\longleftarrow$ StAR

B

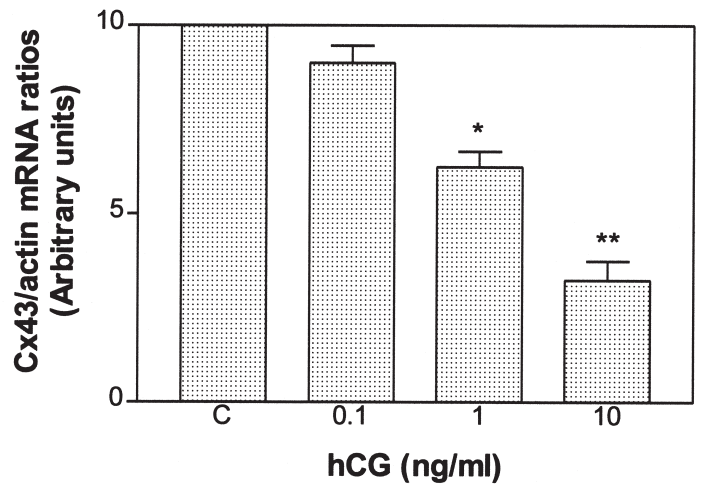

Figure 3 Dose-response curve of the effect of hCG on Cx43 gene expression. Purified Leydig cells were obtained from 55- to 65-day-old rats. Cells were cultured overnight and then treated with hCG $(0 \cdot 1,1$ or $10 \mathrm{ng} / \mathrm{ml})$ for $6 \mathrm{~h}$. Total RNAs were extracted for Northern blot analyses. (A) A representative blot.

(B) Cx43/actin mRNA ratios. Results are the mean \pm S.E. of three separate experiments. ${ }^{*} P<0 \cdot 05,{ }^{* *} P<0 \cdot 01$ compared with controls without hCG treatment.

Cx43 transcript increased dramatically by day 40 , with a level about 7-fold higher than that of day 20 rat Leydig cells. Cx43 mRNA levels remained in high levels in 65- and 80-day-old rat Leydig cells. Increased Cx43 mRNA expression correlated with increased P450 scc mRNA levels.

\section{Effects of hCG on Cx43 mRNA levels}

Since $\mathrm{Cx} 43$ gene expression correlated with male rat sexual maturation, we evaluated the effects of hCG on Cx43 mRNA levels. Purified Leydig cells (60-day-old rats) were cultured overnight and hCG $(10 \mathrm{ng} / \mathrm{ml})$ was then added for various periods of time. $\mathrm{hCG}$ inhibited Cx43 mRNA expression as early as $2 \mathrm{~h}$ and reached a nadir by $24 \mathrm{~h}$ (Fig. 2). In contrast, P450 scc mRNA levels were increased dramatically by hCG treatment. hCG also increased testosterone formation from basal $3 \cdot 2 \pm 0 \cdot 4$ $($ mean \pm s.E.; $n=3) \mathrm{ng} / \mathrm{ml}$ to $95 \cdot 2 \pm 5 \cdot 1 \mathrm{ng} / \mathrm{ml}(P<0 \cdot 001)$ by $24 \mathrm{~h}$. Figure 3 shows the dose-response curve of

\section{A $\quad$ 8-br-cAMP (0.1 mM)}

$0 \quad 6 \quad 24 \mathrm{~h}$
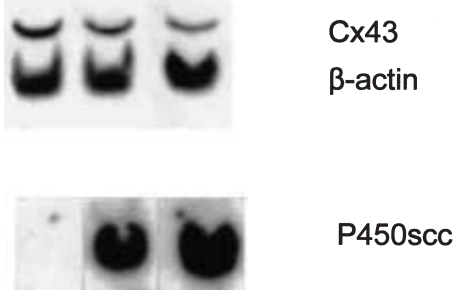

B

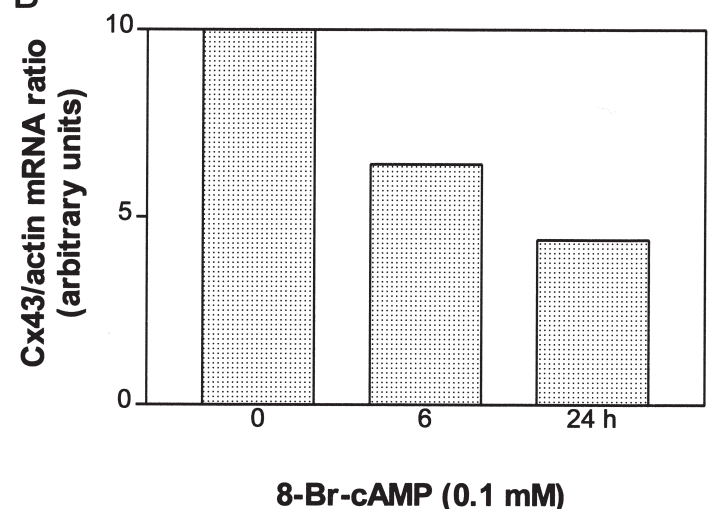

Figure 4 Effects of 8-bromo-cAMP on $\mathrm{Cx} 43$ gene expression. Purified adult Leydig cells were cultured overnight. Cells were then treated with 8-bromo-cAMP $(0 \cdot 1 \mathrm{mM})$ for 6 or $24 \mathrm{~h}$. Total RNAs were extracted for Northern blot analyses. (A) A representative blot; similar results were obtained with two other separate experiments. (B) Cx43/actin mRNA ratios

Cx43 in response to hCG. Purified Leydig cells were cultured overnight. After medium change, hCG $(0 \cdot 1,1$ or $10 \mathrm{ng} / \mathrm{ml}$ ) was added and cultures were continued for an additional $6 \mathrm{~h}$. hCG caused a dose-dependent inhibition of Cx43 mRNA expression; in contrast, StAR mRNA levels were increased markedly.

\section{Effects of cAMP on Cx43 mRNA expression}

The effect of hCG is mediated by the adenylate cyclasecAMP pathway (Dufau 1988). We next evaluated the effect of 8-bromo-cAMP on $\mathrm{Cx} 43$ gene expression. Purified Leydig cells were cultured overnight. After medium change, the cells were treated with 8-bromocAMP $(0.1 \mathrm{mM})$. As shown in Fig. 4 , treatment of cells with 8-bromo-cAMP for 6 and $24 \mathrm{~h}$ reduced $\mathrm{Cx} 43$ mRNA levels by 36 and $56 \%$ respectively, comparable to that observed with hCG treatment. In contrast, P450 scc mRNA levels increased markedly in response to 8-bromo-cAMP. Testosterone levels in the supernatant 

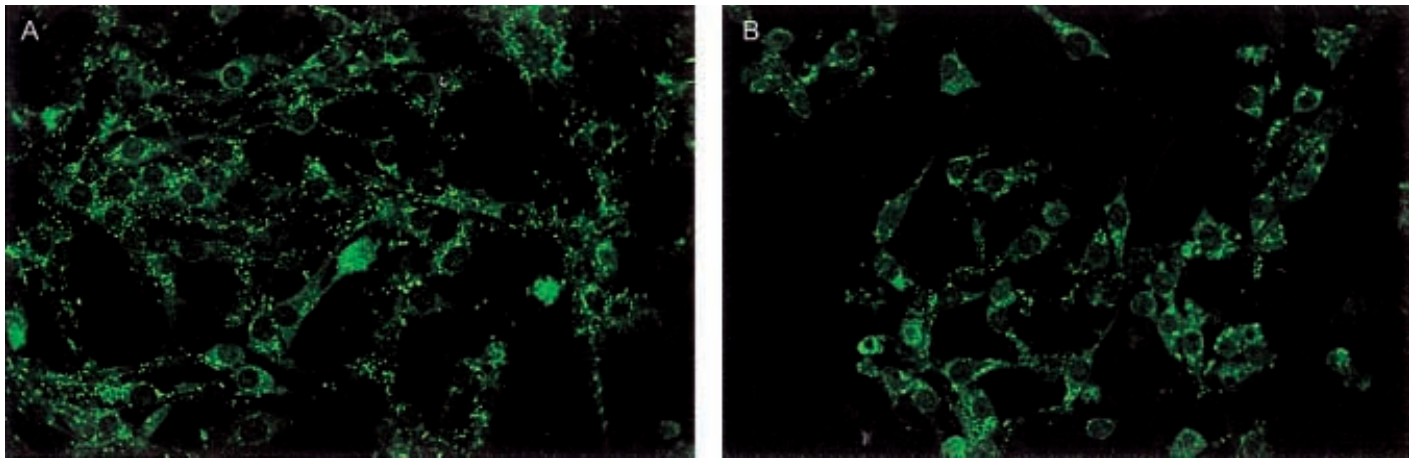

C

Granules on membrane

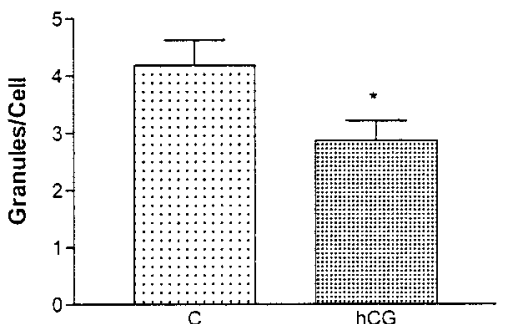

Granules in cytoplasm

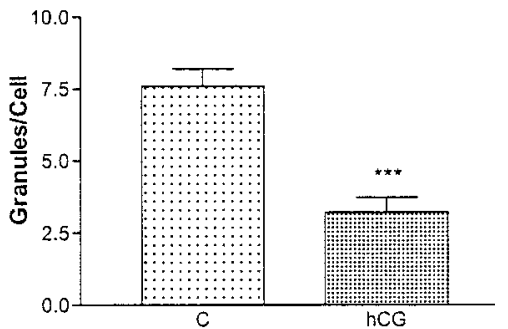

Granules in Whole Cell

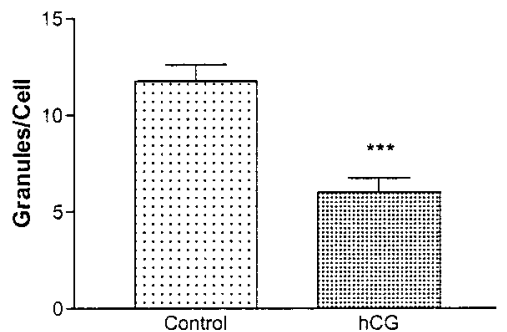

Figure 5 Immunofluorescence staining of Leydig cells. Purified adult Leydig cells were cultured overnight. After medium change, cells were treated with hCG $(10 \mathrm{ng} / \mathrm{ml})$ for $24 \mathrm{~h}$. Leydig cells were stained with anti-Cx43 monoclonal antibody. (A) Control, (B) hCG treated. (C) Quantitative measurement with the Sigmascan Pro 4 program of immunostaining. ${ }^{*} P<0 \cdot 02$; ${ }^{* * *} P<0 \cdot 001$ compared with controls without hCG treatment.
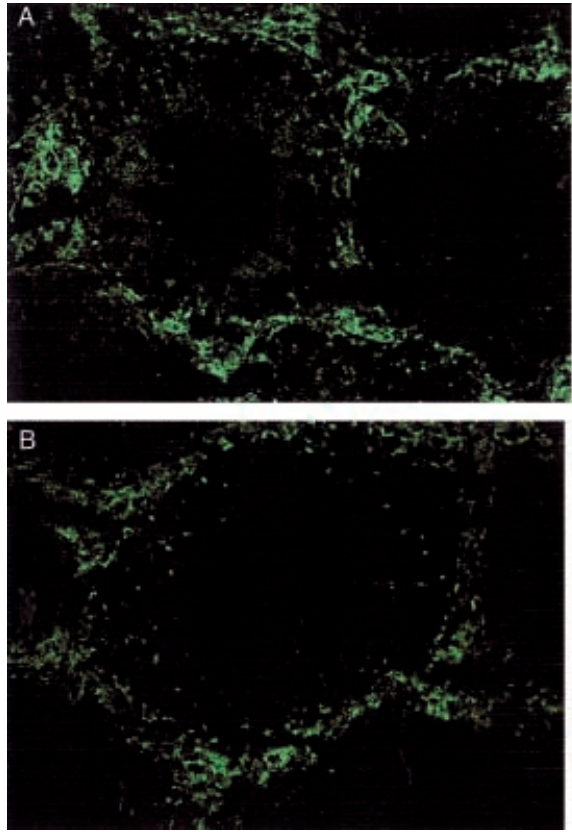
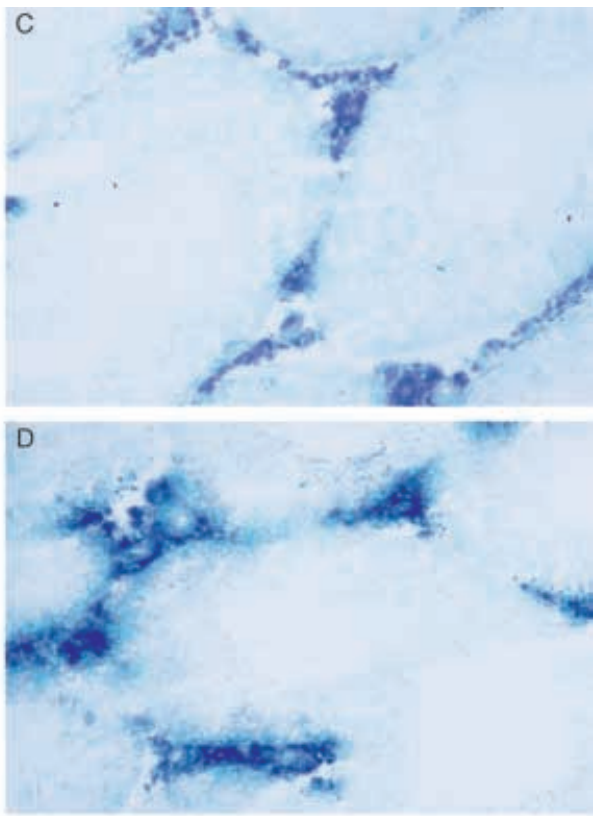

Figure 6 In vivo effect of hCG on Cx43 gene expression. Sixty-five-day-old rats were treated with hCG (300 ng i.p.) and testes were removed $24 \mathrm{~h}$ later. Section was stained with anti-Cx43 monoclonal antibody and immunofluorescence; (A) control, (B) hCG treatment. Frozen section of testes revealed that these interstitial cells were stained positive for 3 $\beta$-HSD; (C) control, (D) hCG treatment. 
were also increased markedly from basal levels of $4 \cdot 2 \pm$ $0 \cdot 3$ to $102 \pm 5 \cdot 6 \mathrm{ng} / \mathrm{ml}(P<0 \cdot 001)$ by 8 -bromo-cAMP treatment.

Effects of hCG on Cx43 protein levels in vivo and in vitro

In order to confirm that hCG indeed down-regulated $\mathrm{Cx} 43$ gene expression, primary cultured Leydig cells were stained with anti-Cx43 monoclonal antibody and immunofluorescence staining. Control Leydig cells without hCG treatment stained strongly positive with multiple punctate signals (Fig. 5A). hCG treatment for $24 \mathrm{~h}$ reduced the $\mathrm{Cx} 43$ signal; in addition, the punctate signals were redistributed to the cell membrane (Fig. 5B). Figure 5C shows quantitative measurement of $\mathrm{Cx} 43$ immunofluorescence. hCG treatment decreased $\mathrm{Cx} 43$ signals by more than $49 \%$ in the whole cells. We also treated 65 -day-old rats with hCG (5 units i.p.) and testes were removed $24 \mathrm{~h}$ later. Frozen section of testes revealed that these interstitial cells stained positive for $3 \beta-\mathrm{HSD}$ (Fig. 6). 3 $\beta-\mathrm{HSD}$ activity increased following hCG treatment while $\mathrm{Cx} 43$ staining of Leydig cells was reduced and strong punctate immunostaining of $\mathrm{Cx} 43$ was observed on the surface of Leydig cells. The adjacent seminiferous tubules were only weakly stained $24 \mathrm{~h}$ after hCG treatment (Fig. 6).

\section{Discussion}

In the present study, we demonstrated that $\mathrm{Cx} 43$ is expressed in rat Leydig cells and that its expression increases with age, reaching a plateau by day 40 . hCG and 8-bromo-cAMP increase Leydig cell steroidogenesis and steroidogenic enzyme mRNA levels but down-regulate $\mathrm{Cx} 43$ and cause a redistribution of $\mathrm{Cx} 43$ to the periphery of the cells.

Leydig cells occur as aggregates of cells interconnected by gap junctions that coordinate their secretory activity. A total of 13 mammalian gap junction proteins, known as connexins, have been cloned (Goodenough et al. 1996, Kumar \& Gilula 1996). Five of these have been identified in the rat testis (Kadle et al. 1991, Risley et al. 1992, Tan et al. 1996). Cx33 and Cx43 are expressed in Sertoli cells in a stage- and age-dependent manner (Risley et al. 1992). Cx26 and Cx32 were localized faintly in the apical region of the seminiferous epithelium (Risley et al. 1992). Cx37 is localized in the endothelia of blood vessels, whereas only Cx43 is localized in the membrane appositions between Leydig cells and in some Sertoli-Sertoli gap junctions (Tan et al. 1996). Expression of Cx43 in Leydig cells increases with age and reaches maximum levels of expression in the adult (Risley et al. 1992), which is consistent with the idea that gap junctional communication is involved in the control of hormone secretion. Using purified Leydig cell preparations, we found in the present study that $\mathrm{Cx} 43$ is expressed in 20-day-old rat Leydig cells and reaches a plateau by day 40. Tan et al. (1996) reported that $\mathrm{Cx} 43$ in the intersitium was localized predominantly to Leydig cell gap junctions. In the tubules, Cx43 was distributed in linear arrays at the periphery of tubules, between the basal and adluminal compartments, and in the region containing the Sertoli occluding junctions. Pellitier (1995) showed that Cx43 is present between Leydig cells in the fetal testis. The appearance of $\mathrm{Cx} 43$ concurred with the onset of spermatogenesis. In the seminiferous epithelium, the distribution of $\mathrm{Cx} 43$ coincided with the gap junctions of the Sertoli cell junctional blood barrier in guinea pigs. The distribution of $\mathrm{Cx} 43$ correlated with germ cell differentiation in a stage-dependent manner (Pellitier 1995). Gap junctions in pairs of Leydig cells mechanically dissociated from mouse testes have been studied with the double whole cell patchclamp technique (Varanda \& Campos de Carvalho 1994). Leydig cells were found to be extensively coupled by dye injection and electrophysiological measurements.

The effects of cAMP on Cx43 gene expression have been reported previously in various cell systems. Mehta et al. (1992) and Schiller et al. (1992) reported that forskolin, an activator of adenylate cyclase, increased Cx43 mRNA 6-fold in a hepatoma cell line, with the increase preceding any detectable increase in dye coupling. Atkinson et al. (1995) investigated the exposure of a mouse mammary tumor cell line, MMT22, to 8-bromo-cAMP. An increase of permeance was noted within $30 \mathrm{~min}$ of treatment and increased 4 -fold by $24 \mathrm{~h}$. The permeability change was accompanied by an increase in gap junction. However, Cx43 mRNA and total cellular content of $\mathrm{Cx} 43$ did not change. In our present study, we found that exposure of Leydig cells to 8-bromo-cAMP or hCG decreased Cx43 mRNA levels. However, Cx43 was redistributed to the cell membrane, suggesting that a greater proportion of $\mathrm{Cx} 43$ was utilized for channel formation.

In conclusion, gap junction channels of rat Leydig cells are regulated by hCG both in vivo and in vitro. hCG increased StAR and P450 scc mRNA expression in Leydig cells, but reduced $\mathrm{Cx} 43$ expression. Most importantly, hCG caused a redistribution of $\mathrm{Cx} 43$.

\section{Acknowledgements}

This work was supported by the US Department of Veterans Affairs Medical Research Fund (to T L).

\section{References}

Atkinson MM, Lampe PD, Lin HH, Kollander R, Li X-R \& Kiang DT 1995 Cyclic AMP modifies the cellular distribution of connexin43 and induces a persistent increase in the junctional permeability of mouse mammary tumor cells. Journal of Cell Science 108 3079-3090. 
Caveney S 1985 The role of gap junctions in development. Annual Review of Physiology 47 19-35.

Dufau ML 1988 Endocrine regulation and communicating functions of the Leydig cell. Annual Review of Physiology 50 483-508.

Goodenough DA, Goliger JA \& Paul DL 1996 Connexins, connexons, and intercellular communication. Annual Review of Biochemistry $\mathbf{6 5}$ 475-502.

Kadle R, Zhang JT \& Nicholson BJ 1991 Tissue-specific distribution of differentially phosphorylated forms of Cx43. Molecular and Cellular Biology 11 363-369.

Kawa K 1987 Existence of calcium channels and intercellullar coupling in the testosterone secreting cells of the mouse. Journal of Physiology 393 647-666.

Klinefelter GR, Hall PF \& Ewing LL 1987 Effect of luteinizing hormone deprivation in situ on steroidogenesis of rat Leydig cells purified by a multi-step procedure. Biology of Reproduction $\mathbf{3 6}$ 769-783.

Kumar NM \& Gilula NB 1996 The gap junction communication channel. Cell 84 381-388.

Lin T 1985 The role of calcium/phospholipid-dependent protein kinase in Leydig cell steroidogenesis. Endocrinology 117 119-126.

Lin T, Wang D, Nagpal ML, Chang W \& Calkins JH 1992 Down regulation of Leydig cell insulin-like growth factor-I gene expression by interleukin-1. Endocrinology 130 1217-1224.

Lin T, Hu J, Wang D \& Stocco DM 1998 Interferon- $\gamma$ inhibits the steroidogenic acute regulatory protein messenger ribonucleic acid expression and protein levels in primary cultures of rat Leydig cells. Endocrinology 139 2217-2222.

Loewenstein WR 1979 Junctional intercellular communications and the control of growth. Biochimica et Biophysica Acta 560 1-65.
Loewenstein WR 1981 Junctional intercellular communications: The cell-to-cell membrane channels. Physiological Reviews 61 829-913.

Mehta PP, Yamamoto M \& Rose B 1992 Transcription of the gene for the gap junctional protein connexin 43 and expression of functional cell-to-cell channels are regulated by cAMP. Molecular Biology of the Cell 3 839-850.

Pellitier R-M 1995 The distribution of connexin 43 is associated with the germ cell differentiation and with the modulation of the Sertoli cell junctional barrier in continual (Guinea pig) and seasonal breeders' testes. Journal of Andrology 16 400-409.

Risley MS, Tan IP, Roy C \& Saez JC 1992 Cell-, age- and stagedependent distribution of connexin43 gap junctions in testes. Journal of Cell Science 103 81-96.

Schiller PC, Mehta PP, Roos BA \& Howard GA 1992 Hormonal regulation of intercellular communication: parathyroid hormone increases connexin 43 gene expression and gap junctional communication in osteoblastic cells. Molecular Endocrinology 6 $1433-1440$.

Tan IP, Roy CR, Saez JC, Saez CG, Paul DL \& Risley MS 1996 Regulated assembly of connexin33 and connexin 43 into rat Sertoli cell gap junctions. Biology of Reproduction 54 1300-1310.

Varanda WA \& Campos de Carvalho AC 1994 Intercellular communication between mouse Leydig cells. American Journal of Physiology 267 C563-C569.

Received 29 March 1999

Revised manuscript received 6 December 1999 Accepted 30 March 2000 